\title{
Transthoracic oesophagotomy in managing impacted foreign body at lower oesophagus
}

\author{
I.H.D.S Pradeep, S. Ilangamge, D.K. Rupasingha \\ Department of Thoracic surgery, National hospital for respiratory diseases, Welisara, Sri Lanka
}

Key words: Transthoracic oesophagotomy; oesophageal foreign body

\section{Introduction}

Accidental ingestion of foreign bodies is very common in paediatric and elderly patients. In elderly it is commonly seen in patients with poor sensory perception and psychiatric disorders. Ingestion of dental appliances is the commonest cause seen in normal adults. Cervical oesophagus is the commonest site of impaction followed by mid and lower oesophagus. Most of these foreign bodies don't require a surgical intervention and will pass through the gastrointestinal tract without a major sequel. Out of these 10-20\% may require endoscopic removal and nearly $1 \%$ will require formal thoracoscopic or open surgical intervention. Here we present a case of removal of dental prosthesis impacted in lower oesophagus via transthoracic oesophagotomy.

\section{Case presentation}

A 54yr old female presented with dysphagia and odynophagia for 1 month following an ingestion of an upper dental prosthesis. With progressive symptoms patient presented to E.N.T department and subsequently attempted endoscopic removal via rigid oesophagoscopy. Patient was referred to thoracic surgical unit following failed endoscopic procedure and patient was planned for thoracotomy and oesophagotomy followed by primary repair.

Prior to surgery patient underwent orogastro-duodenoscopy which revealed the foreign body at $34 \mathrm{~cm}$ form the incisor tooth covered with mucosa and granulation tissue incorporating it to oesophageal wall. The gastro oesophageal junction was at $38 \mathrm{~cm}$ from incisors. On contrast enhanced CT imaging of thorax there were no features of oesophageal perforation and site of impaction couldn't be seen radiologically. Patient underwent left sided postero lateral thoracotomy via 8th intercostal space and there were no features of oesophageal perforation. On entry to the thoracic cavity an intercostal muscle flap was harvested based on

Correspondence: I.H.D.S Pradeep

E-mail: samaniddagoda@gmail.com

Received: 15-10-2017 Accepted: 13-12-2017

(iD) http://orcid.org/0000-0003-3526-1684

DOI: http://doi.org/10.4038/sljs.v35i4.8440

The Sri Lanka Journal of Surgery 2017; 35(4): $42-43$ posterior intercostal arteries. On palpation site of impaction identified and it was retrieved via longitudinal ophagotomy done in between two stay sutures. Oesophagotomy repaired with interrupted 30 PGA sutures in 2 layers and reinforced with an Intercostal muscle flap ( Figure 1). Her post-operative period was uneventful with a period of 7 days of parenteral feeding and subsequently established on oral feeding after confirmation of no anastomosis leak clinically and contrast study (Figure 2). Patient was discharged on post op day 10 to be followed up at the clinic in 6 weeks.

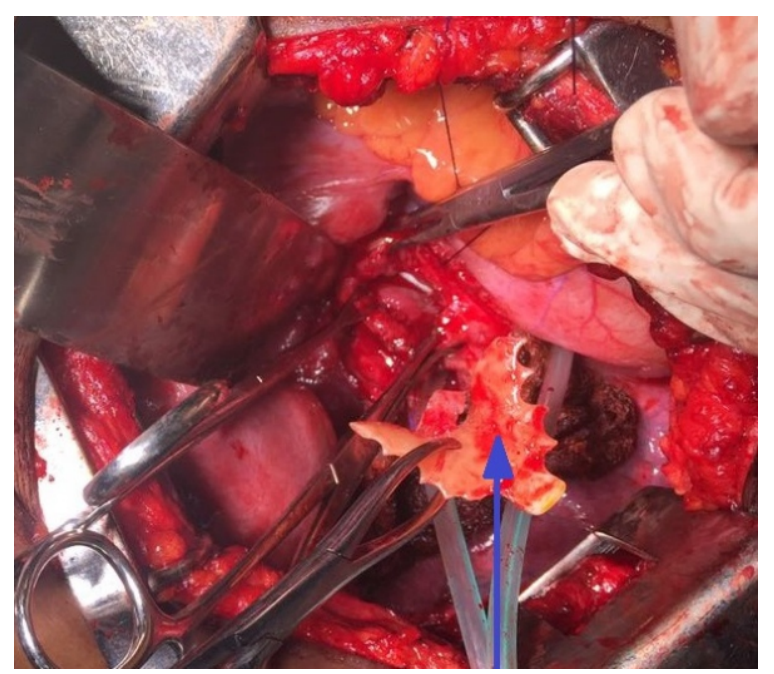

Figure 1. Retreval of foreign body via esophagotomy

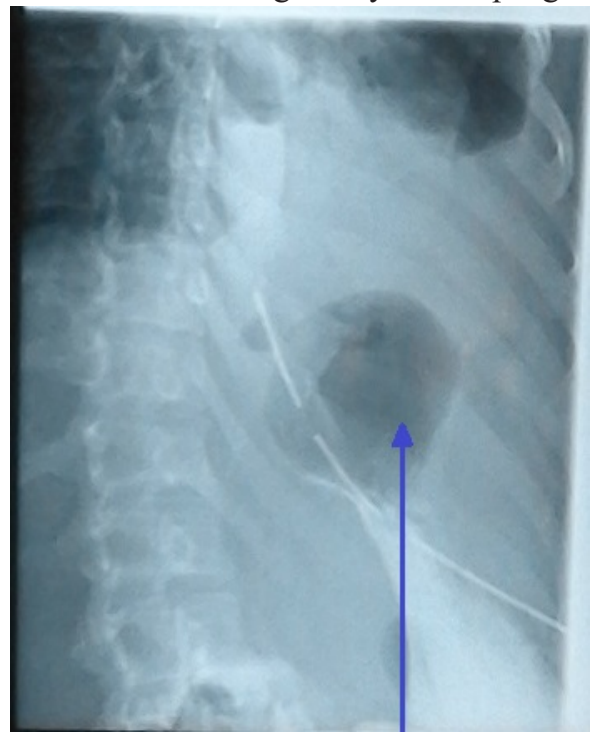

Figure 2. Normal Oral contrast study 


\section{Discussion}

With the rising population of elderly people the use of dental prosthesis is high in number. This will result in increased chance of accidental ingestion of dental prosthesis. Depending on the size, shape, consistency, material and nature of the edges will determine the fate of the ingested prosthesis, especially the large ones with spiky edges require formal surgical intervention. Patient may present with wide array of clinical presentations ranging from dysphagia and odynophagia to life threatening complications. Oesophageal perforations along with empyema, mediastinitis and aortoesophageal fistula requires prompt diagnosis and treatment to reduce mortality associated with it. Patients presenting with late onset symptoms has the highest chance of perforation and associated complications.

Detailed clinical history along with radiological investigations and upper GI endoscopy will reveal the site and the nature of the substance which is ingested. This is a challenging process in children and elderly who cannot give a reliable history.

Endoscopic retrieval plays a major role as a minimally invasive method in dealing with foreign bodies in the oesophagus. This is more favourable in early presentation where there is less incorporation of the foreign body to oesophageal wall. Once the foreign body is incorporated to the oesophageal wall it requires formal thoracoscopic or thoracotomy approach to explore the site proceeded with oesophagomyotomy. Depending on the degree of contamination and nature of the oesophageal wall most of the time it is possible to proceed with primary suturing of the esophagotomy. As a method of reinforcing the anastomotic site an intercostal or pleural flap can be used. In patients presenting with empyema and mediastinitis removal of the septic focus along with discontinuation of the oesophagus via cervical oesophagostomy and feeding jejunostomy is advisable as a damage control approach.

Based on the published data oesophagotomy via thoracotomy and thoracoscopic approaches are safe procedures in managing delayed presentations of foreign body impacted in the oesophagus. Rigid or flexible Endoscopy plays a major role in early presentations. Patient should be routinely followed at clinics to detect post oesophagotomy stricture formation which may require dilatation later.

\section{References}

1. Fujino K, Mori T, Yoshimoto K, Ikeda K, et al. Oesophageal fish bone migrating to the lung: report of a case. Kyobu Geka. 2012, 65 (10): 5-922.

2. Ruckbeil O, Burghardt J, Gellert K: Thoracoscopic removal of a transesophageal ingested mediastinal foreign body. Interact Cardiovasc Thorac Surg. 2009, 9 (3): 556-7. https://doi.org/10.1510/icvts.2009.209676

3. Palanivelu C, Rangarajan M, Parthasarathi R, Senthilnathan P: Thoracoscopic retrieval of a "smiling" foreign body from the proximal oesophagus. Surg Laparosc Endosc Percutan Tech. 2008, 18: 325-328.

https://doi.org/10.1097/SLE.0b013e3181661919

4. Davies B, Black E, Vaughan R: Thoracoscopic drainage of and foreign body removal from a posterior mediastinal abscess. Eur J Cardiothorac Surg. 2004, 25 (5): 897-8. https://doi.org/10.1016/j.ejcts.2003.12.042

5. Dalvi AN, Thapar VK, Jagtap S, Barve DJ, et al. Thoracoscopic removal of impacted denture: report of a case with review of literature. J Minim Access Surg. 2010, 6 (4): 119-21. https://doi.org/10.4103/0972-9941.72600

\section{Learning Points:}

- In early presentations endoscopic retrieval plays a major role as a minimally invasive method in dealing with foreign bodies in the oesophagus.

- Esophagotomy via thoracotomy and thoracoscopic approaches are safe procedures in managing delayed presentations of foreign bodies impacted in the oesophagus. 